\title{
Lipocalin-2 Measurement
}

National Cancer Institute

\section{Source}

National Cancer Institute. Lipocalin-2 Measurement. NCI Thesaurus. Code C106539.

The determination of the amount of lipocalin-2 present in a sample. 